\title{
Sensible/visible: les hijes de detenides desaparecides en Hasta que mueras, de Raquel Robles (2019) y Yo la quise (2020), de Josefina Giglio
}

\author{
Sensible/visible: The Children of Forced \\ Disappearance Victims in Hasta que mueras, by \\ Raquel Robles (2019) and Yo la quise (2020) by \\ Josefina Giglio
}

\begin{abstract}
Resumen
La literatura de hijos de detenides desaparecides, entre las que se cuentan la de Raquel Robles y Josefina Giglio, que atravesaron la experiencia traumática de la última dictadura argentina cívico militar eclesial empresarial en 1976, ha sido objeto de múltiples abordajes por parte de la crítica vernácula (Reati, Domínguez, Basile), o extranjera (García Díaz, Bolte, Gatti, et al). En este estudio nomino al colectivo con minúsculas con el fin de desplazar el carácter institucional que si bien es importante puede llegar a reducir la perspectiva que intento desplegar. Perspectiva que se centra en interrogar qué aporta la escritura de hijes de desaparecides en términos de complejidad a los estudios literarios en el marco de la articulación memoria-literatura. Así, advierto un cúmulo de escrituras, ya sean en el múltiple arco de la narrativa o poesía, donde la asunción de la voz que enuncia, en algunos casos, trabaja la experiencia en primera persona a partir de estilos ya registrados en la literatura, aunque las vivencias de les autores potencian escrituras difíciles de colocar en corrientes literarias precisas. Como si la literatura fuera a visibilizar la tensión misma que implica su politicidad a partir de las voces narrativas con un pie en la experiencia vivida y otro en el laboratorio creador; también es preciso señalar que dicha experiencia coloca a la política estatal como nodo central ya que reconfiguró la vida no solo de los autores sino de toda sociedad, en este caso argentina. En las novelas seleccionadas estamos frente a lo que Jacques
\end{abstract}


Rancière $(2015,2011)$ entiende como un principio de acción, a partir del cual ni la literatura ni los lectores podemos estar alejados de un nuevo ethos. A partir de este es posible conectarnos con ciertas experiencias que se desprenden en este caso de ambas novelas y que afectan nuestra percepción de la realidad y de la historia. La literatura argentina, nacida en el seno mismo del estado-nación, no es la misma luego que los hijos una vez que intervinieron la calle en la segunda mitad de la década de los 90 del siglo pasado para pedir justicia, toman la palabra en el nuevo milenio y escriben experiencias que nos afectan a todos, y que remodelan los modos de pensar la política, la literatura y la historia.

Palabras claves

Literatura; inter memoria; hijes.

\begin{abstract}
The literature of the children of forced disappeared victims, including that of Raquel Robles and Josefina Giglio, who went through the traumatic experience of the last Argentine civicmilitary ecclesial business dictatorship in 1976, has been the subject of multiple approaches by vernacular critics (Reati, Domínguez, Basile), or foreign (García Díaz, Bolte, Gatti, et al). In this study, I name the group as lowercase in order to displace the institutional character that, although important, can reduce the perspective that I am trying to display. This perspective focuses on questioning what the writing of children of the disappeared contributes in terms of complexity to literary studies within the framework of memory-literature articulation. Thus, I notice an accumulation of writings, whether in the multiple arc of narrative or poetry, where the assumption of the voice that enunciates, in some cases, works the experience in the first person from styles already registered in literature, although the experiences of the authors enhance writings that are difficult to place in literary trends. As if literature were to make visible the very tension that its politicity implies from the narrative voices with one foot in the lived experience and the other in the creative laboratory; It is also necessary to point out that this experience places state politics as the central node since it reconfigured the life not only of the authors but of all society, in this case Argentina. In the selected novels we are faced with what Jacques Rancière $(2015,2011)$ understands as a principle of action, from which neither literature nor readers can be far from a new ethos. From this it is possible to connect with certain experiences that emerge in this case from both novels and that affect our perception of reality and history. Argentine literature, born in the very bosom of the nationstate, is not the same after the sons once they intervened in the street in the second half of the 90s of the last century to demand justice, they speak in the new millennium and write experiences that affect us all, and that reshape the ways of thinking politics, literature and history.
\end{abstract}




\section{Introducción}

La literatura de hijes de detenides desaparecides escrita por les otrora niñes, que atravesaron la experiencia traumática de la última dictadura argentina cívico militar eclesial empresarial en 1976, ha sido objeto de múltiples abordajes por parte de la crítica vernácula (Reati, Domínguez, Basile, etc.), o extranjera (García Díaz, Bolte, Gatti, et al). En este estudio nomino al colectivo con minúsculas con el fin de desplazar el carácter institucional que si bien es importante puede llegar a reducir la perspectiva que intento desplegar en este escrito. Perspectiva que se centra en interrogar qué aporta la escritura de hijes de desaparecides en términos de complejidad a los estudios literarios en el marco de la articulación memorialiteratura.

La problematicidad de la relación entre memoria y posmemoria, abordada por Beatriz Sarlo, a partir de la perspectiva de Marianne Hirsch, en su libro Tiempo pasado. Cultura de la memoria y giro subjetivo. Una discusión (2005) permite alumbrar la amplia producción de hijes en el arte y la centralidad que porta la primera persona y el testimonio. Sin embargo, es posible elegir otros ingresos al corpus de hijes; este sacudió los cimientos del canon, de la articulación entre novela, autobiografía y testimonio en sus múltiples variantes. Otra dimensión a destacar es la profesionalización de les hijes como escritores, cuando al despuntar el nuevo milenio comienzan a publicar; los nombres de Félix Bruzzone, Raquel Robles, Francisco Garamona, Ernesto Semán, Eva Pérez, Ángela Urondo Raboy, Julián Axat, Emiliano Bustos, Nicolás Prividera, entre otros, circularon por entonces tímidamente por las academias argentinas pero con el paso del tiempo adquieren reconocimientos importantes, entre los cuales cabe destacar el premio Clarín para Perder (2008) de Raquel Robles; investigaciones académicas, artículos, traducciones, dirección de editoriales y premios señalan la visibilidad de les hijes que si bien no abandonan la calle, algunes conquistan otro espacio de visibilidad, la literatura. 
Cuando convoco la imagen de la sacudida es porque advierto un cúmulo de escrituras, ya sean en el múltiple arco de la narrativa o poesía, donde la asunción de la voz que enuncia, en algunos casos, trabaja la experiencia en primera persona a partir de estilos ya registrados en la literatura, aunque las vivencias de les autores potencian escrituras difíciles de colocar en corrientes literarias al "uso". ${ }^{1}$ Como si la literatura fuera a visibilizar la tensión misma que implica su politicidad a partir de las voces narrativas con un pie en la experiencia vivida y otro en el laboratorio creador; también es preciso señalar que dicha experiencia coloca a la política estatal como nodo central ya que reconfiguró la vida no solo de los autores sino de toda sociedad, en este caso argentina. Los textos seleccionados implican en Hasta que mueras, de Robles, una madurez escrituraria en la cual el informe forense, el diario o la noticia son intervenidos por la voz narrativa a los fines de mostrar cómo la literatura puede ser una forma de ajuste de cuentas frente a la impunidad, y al mismo tiempo dicha voz, encarnada en un escritor, también alude a la complejidad de componer una narración cuya protagonista, Nadia, hija de militantes, es una asesina serial. En cuanto a la primera novela de Josefina Giglio Yo la quise $e^{2}$ advierto que una de las preocupaciones centrales es el cómo narrar; esta se proyecta en un escritor, Ricardo Piglia, cuyo relato en el primer y último capítulo se construye a partir de sus recuerdos ensamblados con otras voces entre la que se cuenta la de Vibel, militante desaparecida y madre de la autora; expresa Piglia, como creatura de Giglio, y en referencia a su joven amada:

¿Cómo contar esa intensidad? ¿El recuerdo, ampliado con los años, es más fuerte que la verdad? ¿Ella recordaría lo mismo que yo ahora? ¿Es posible

${ }^{1}$ Teresa García Díaz señala con acierto la diferencia entre autobiografía y autoficción. Diferencia que contrasta el todo y el fragmento para las narraciones inscriptas en el corpus literario luego del golpe de Estado de 1976, entre la que se cuenta la de Robles y podría incluir en esta estela la primera novela de Giglio (García Díaz 182).

${ }^{2}$ Todas las citas que realizaré de ambas novelas siguen a las siguientes ediciones: Hasta que mueras (2019), de Raquel Robles, Factotum ediciones y Yo la quise (2020), de Josefina Giglio, editorial Universidad Nacional de La Plata. Agradezco a Josefina Giglio por cederme el pdf de su primera novela. 
recordar la verdad? ¿Y contarla?) Vuelvo a acomodar el papel en la máquina de escribir, desarmo y armo la pila de libros. Necesito otras palabras, palabras que nunca he usado, para contar esta historia. ¿Sirve hablar de lo sucedido? Sirve para explicar lo que queríamos y lo que finalmente sucedió. Al menos sirve para recordar quién era yo. Si pudiera reconstruir todas las circunstancias que nos llevaron a estar juntos y todas aquellas por las cuales dejamos de estarlo, tendría la historia. (Giglio 35).

Así, en la estela de Jacques Rancière en Política de la literatura (2011) es posible pensar un principio de acción a partir del cual ni la literatura ni los lectores podemos estar alejados de un nuevo ethos, es decir, un posible camino y proyecto de escrituras que nos permitan conectarnos con ciertas experiencias históricas que se desprenden de las novelas y que afectan nuestra percepción. Es decir, la experiencia histórica puede provenir también de la literatura que remodela los espacios y las palabras; asegura el filósofo francés a partir de su categoría "reparto de lo sensible":

La expresión 'política de la literatura' implica, entonces, que la literatura interviene en tanto que literatura en ese recorte de los espacios y los tiempos, de lo visible y lo invisible, de la palabra y el ruido. Interviene en la relación entre las prácticas, entre formas de visibilidad y modos de decir que recortan uno o varios espacios comunes. (16-17)

Sin dudas, la perspectiva rancereana toca el centro de la democratización de la categoría "literatura", e invita a superar las limitaciones de lo que es ficción o no, de la intensidad histórica de los "yo" que pueblan las historias para dejar paso a qué y quiénes visibilizan. En esta dirección, advierto que el título de la novela es un verso del poema de Juan Gelman que antecede al relato. Tanto esta mención como el tema de la venganza borgeana señalan la doble inscripción literaria que pulsa la historia narrada. En cuanto a la novela de Giglio, su título es extraído de una carta 
CATEDRAL TomAda: Revista de crítica literaria latinoamericana / Journal of Latin American Literary Criticism Sensible/visible: les hijes de detenides desaparecides en Hasta que mueras, de Raquel Robles (2019) y Yo la quise (2020), de Josefina Giglio

mecanografiada por Piglia y dirigida a la hija de Vibel, es decir, a Josefina Giglio. Así, los títulos y los epígrafes, en tanto que préstamos desde la literatura son centrales en la política de la memoria. El título como la dedicatoria de la novela de Giglio a sus padres, Vibel y Carlos, trazan no solo los límites resbaladizos entre lo que es ficción o no, sino que muestran cómo la literatura también es una forma de hacer historia. Rancière insiste en la falacia de extrapolar ficción y mentira; antes bien, en la ficción podemos encontrar algunas verdades que emergen de ciertos espacios y palabras que tocan la esfera de la intimidad del yo; esfera que habla de su politicidad.

La cultura argentina, nacida en el seno mismo del estado-nación, no es la misma luego que les hijes intervinieron la calle, en la segunda mitad de la década de los 90 del siglo pasado, para pedir justicia ${ }^{3}$. Dicho acontecimiento continúa en el nuevo milenio, espacio tiempo donde la calle se articula con la palabra literaria ya que algunes la toman y escriben experiencias que nos afectan a todes, con lo cual, como anticipé más arriba, remodelan los modos de pensar lo político, la historia y el arte, en este caso, la literatura. ${ }^{4}$ En esta estela, se orientan las reflexiones de Teresa Basile cuando alude a una literatura que nace a partir de la

${ }^{3}$ García Díaz expresa: "El 5 de abril de 1976, a menos de dos semanas del golpe de Estado en Argentina, secuestran a Gastón Robles (Secretario de Agronomía en el Gobierno de Cámpora) y a Flora Pasatir mientras sus niños duermen; la madre de Gastón es la única testigo de los hechos. Lo sucedido trasciende brutalmente la vida de Raquel Robles y de su pequeño hermano". (García Díaz 181). En cuanto a Josefina Giglio es hija de Vibel Cazalas (detenida-desaparecida en 1977) y Carlos Giglio (detenido-desaparecido en 1974). Giglio es fundadora de H.I.J.O.S.

${ }^{4}$ Gabriel Gatti se refiere a la importancia de la producción artística de hijes en los siguientes términos: "Estamos pues ante un colectivo, el de los hijos de desaparecidos, compuesto por sujetos que han elaborado una cierta experiencia normalizada de la catástrofe, la de los casi cuarenta años pasados desde la desaparición de sus padres. Dije "colectivo" y dije mal, pues ni puede afirmarse que esta forma de experimentar la desaparición forzada sea la de todos los "hijos de" ni que sean solo ellos los que la vehiculan. Por un lado porque estos no hacen grupo, aunque sí hagan a veces grupos, y es seguro que no conforman en conjunto una memoria única, sino memorias diversas, todas ellas cortadas por diferentes marcas de origen, de clase, hasta de edad y género. [...]. En suma, no todos los hijos de desaparecidos se instalan en el vacío para construir identidad.

No obstante, sí puede decirse que de ese lugar, el vacío, brotan muchas de las estrategias desde las que actualmente se encara este fenómeno. En el arte, ya lo vimos, donde se buscan formas de expresión construidos sobre cierta retórica del resto y de la herida; o entre algunos profesionalesarqueólogos, archiveros o psicólogos, por ejemplo-, que trabajan para dar con registros que le permitan desempeñarse con rigor en el universo social que demanda sensibilidad por la ausencia de sentido..." (Gatti 179). 
complejidad que conlleva en los autores-hijes ser partícipe directo de la violencia dictatorial y luego haberse dedicado al cultivo de las letras; expresa Basile:

La figura del escritor se halla tensada conflictivamente entre la posición identitaria de ser "hijo de" y el rol del escritor. ¿Qué se encuentra primero, la condición del escritor o la del hijo? ¿Se escribe porque se es HIJO, y entonces el estatuto del escritor resulta secundario, putativo, sospechado de oportunismo, una ocasión para ingresar al mercado literario por la puerta trasera? ¿Hay que salvar al escritor del HIJO? Por otro lado, la producción literaria y cultural de HIJOS resulta altamente valorada por cierto público, tiene su propia legitimidad, ya que parece ofrecer garantías éticas y hasta se rodea de un aura peculiar. En una conferencia dictada en la Facultad de Humanidades y Ciencias de la Educación de la Universidad Nacional de La Plata, bajo el título de "Literaturas de la memoria. Herederos y entenados" (14 de setiembre de 2016), Raquel Robles se quejaba lúcidamente del mercado que etiquetaba apresuradamente su narrativa bajo la fórmula de "literatura de HIJOS", y reclamaba ser leída simplemente como escritora. Es evidente que se trata de un vínculo problemático y equívoco, surcado por suspicacias y sospechas. Por momentos los HIJOS escritores ensayan otras narrativas que les permitan escapar al rótulo y concretar el deseo de ser escritor, sin más adjetivaciones. Lo cierto es que esa literatura viene a reponer la "biografía" del escritor como principio que reorganiza el campo cultural, una biografía protagonizada por el ADN, por la biología, por el parentesco y la filiación. ¿En qué medida "ser hijo" autoriza la escritura literaria? El desenfado irreverente de algunas voces de los "hijos de", que sobrepasan impunemente las vallas de lo políticamente tolerable, parece ser una de sus prerrogativas: ¿acaso el lector toleraría la burla sobre los desaparecidos en boca de cualquier otro escritor? (24) 
Cabe advertir en la reflexión de Basile una tensión imborrable, ladera vital doble que pulsa en cada caso un diálogo con la historia familiar y social. Un aspecto central para señalar es la tensión entre la biografía y su pasaje al hecho creador es que puede tener diversos tonos entre los cuales se cuenta la ironía y la parodia, entre otros. También es posible señalar que el advenimiento de la escritura de hijes el campo literario estuvo saturado de una literatura de la memoria que no provenía de la experiencia política de les autores. Considero dicho advenimiento como una interrupción enriquecedora que habilita la emergencia de una voz que puede reacomodar dicha experiencia y trabajarla desde la creación literaria. También es preciso señalar la aparición de otras palabras, las de los hijes de represores. Son sus exhijes $^{5}$ quienes levantan la tapa de lo visible y muestran las fisuras familiares y generacionales a través del testimonio; estos renuncian a la genealogía para decir no a una historia que adviene como legado del parentesco sanguíneo pero con la cual no se identifican. Me refiero a la práctica de sus padres y/u otres familiares, de saber y poder ocultar cuerpos, separar a les niñes de sus familias, adulterar identidades, ${ }^{6}$ sustraer bienes materiales de las familias de militantes. También, existe una rica literatura cuya voz narrativa es la de hijes de militares como la cultivada por Federico Jeanmarie con su novela Papá (2003), Leopoldo Brizuela, La última noche (2012) o 1982 (2017), de Sergio Olguín, entre otros.

${ }^{5}$ Un libro central que ilumina esta nueva visibilidad es Escritos desobedientes (2018), recopilación de trabajos del Colectivo Historias Desobedientes. En él emergen los escritos de ex hijes, la experiencia dolorosa vivida que abona y complejiza los procesos de memoria. El proyecto del colectivo es binacional, es decir, chileno-argentino. En este texto es posible observar poemas escritos por ex hijes a sus padres.

${ }^{6}$ Un amplio espectro de reflexiones se desarrolla en Argentina y Chile con respecto a este tema. En Argentina Los nacidos en los 70. Historia de una generación que heredó la tragedia argentina (2016), de Carolina Arenes y Astrid Pikielny es una investigación periodística de la cual resulta una selección de narraciones a partir de las experiencias de diferentes hijes de los 70 recogidas a través de entrevistas. Desde mi perspectiva no solo es reduccionista, cuestión que es inherente a una selección, sino también indistinta; en ella conviven textos firmados por Ricardo Saint Jean como la de Mario Javier Firmenich, hijos de Ibérico Saint Jean, gobernador de facto de Buenos Aires, entre 1976 y 1982, y Mario Firmenich, dirigente Montonero, respectivamente. Asimismo, cabe resaltar que el texto fue editado en el 2016, es decir, momento en el cual la agenda de derechos humanos ingresa a una fase de repliegue bajo el gobierno del presidente Mauricio Macri. 
Si Rancière a partir del reparto de lo sensible otorga a la categoría de lo literario un nuevo sentido como es de reacomodar los lugares de visibilidad, y en consecuencia la de sacar a la luz nuevos decires y sentires, no menos seductor es poder articular la categoría de fantasma o espectro como aquella imagen de memoria que, con su aparición furtiva, da a ver un nuevo orden de lo visible. Sabemos la relevancia que porta la obra tutelar de William Shakespeare Hamlet (1604) en la cual la presencia del espectro del padre del príncipe adviene a la esfera de lo visible con el fin de que su hijo vengue su homicidio por parte de su hermano Claudio. El fantasma borra los límites entre la vida y la muerte, promueve el otro que regresa, e impacta fuertemente en los trabajos de la memoria, tal como lo plantea Jacques Derrida en dos textos centrales Memorias para Paul de Man (2008) y Los fantasmas de Marx (2012). No menos importante es advertir que Hamletpadre profiere al joven príncipe "véngame"; el espectro desconoce la sucesividad, se burla del tiempo pasado-presente ya que en tanto aparecido es una interrupción de la sucesión que pulsa la recordación en la tragedia shakespereana. ${ }^{7}$ Los primeros en convertir a Hamlet-padre en una imagen de la memoria en torno a la dictadura militar es la Generación Salvaje, nacida en La Plata, en el nuevo milenio, a la sombra de la violencia dictatorial ya que son poetas e hijes de detenides

${ }^{7}$ Esa Cosa que no es una cosa, esa Cosa invisible entre sus apariciones, tampoco es vista en carne y hueso cuando reaparece. Esa Cosa, sin embargo, nos mira y nos ve no verla incluso cuando está ahí. Una espectral disimetría interrumpe aquí toda especularidad. Desincroniza, nos remite a la anacronía. Llamaremos a esto el efecto visera: no vemos a quien nos mira. Aunque en su fantasma el rey se parece a sí mismo «como a ti mismo tú te pareces» dice Horacio, esto no impide que mire sin ser visto: su aparición le hace aparecer también invisible bajo su armadura. [...] Otra sugerencia: este algún otro espectral nos mira, nos sentimos mirados por él, fuera de toda sincronía, antes incluso y más allá de toda mirada por nuestra parte, conforme a una anterioridad (que puede ser del orden de la generación, de más de una generación) y a una disimetría absolutas, conforme a una desproporción absolutamente indominable. La anacronía dicta aquí la ley. El efecto visera desde el que heredamos la ley es eso: el sentirnos vistos por una mirada con la que será siempre imposible cruzar la muestra. Como no vemos a quien nos ve, y dicta la ley, y promulga la inyunción, una inyunción por otra parte contradictoria, como no vemos a quien ordena: «jura» (swear), no podemos identificarlo con certeza, estamos entregados a su voz. A quien dice: «Soy el espectro de tu padre», sólo podemos creerle bajo palabra. Sumisión esencialmente ciega a su secreto, al secreto de su origen: primera obediencia a la inyunción, que condicionará a todas las demás. Siempre puede tratarse de algún otro, que puede mentir, disfrazarse de fantasma, y también otro fantasma puede hacerse pasar por éste. Siempre es posible. (Derrida 21-22). 
desaparecides. ${ }^{8}$ Sin embargo, más allá del nombre del fantasma literario sostengo que la recordación de les hijes potencia presencias fantasmales como forma de hacer memoria re distribuyendo, a partir de las diversas voces en los relatos, la resucitación de los seres que por la acción de la violencia política no están entre los vivos. Al mismo tiempo es el discurso literario el que les otorga la vitalidad para visibilizar otra forma de memorizar y de producir cierto tipo de historia en los lindes de la oficialidad. En la ficción o a través de ella, las voces se otorgan ciertos permisos, como los de vengar la impunidad de les represores o brindar ciertas imágenes de familia, de madres e hijas por fuera de los estereotipos. En este proceso de desacomodamiento cabe señalar la importancia del erotismo como dispositivo que configura la memorización, por ejemplo, de Vibel, en la novela de Giglio, ya que aquel potencia un corrimiento del límite que impone la imagen aurática de la mujer militante.

Como anticipé en el inicio de este estudio la producción literaria de hijes se desarrolla a inicios del nuevo milenio conjuntamente con la agenda de los derechos humanos en Argentina, atravesada por conquistas y retrocesos en los juicios de lesa humanidad. Con respecto a esta dimensión Raquel Robles y Josefina Giglio son figuras clave en la fundación de la asociación H.I.J.O.S pero quisiera rescatar más allá de su ostensible militancia lo que ambas escritoras le aportan a la literatura. Esta dimensión es la que me interesa ya que advierto importantes pasajes en el proceso creador como ser dichas o narradas "por", a enunciar en primera persona con el fin de lidiar con sus fantasmas.

\footnotetext{
${ }^{8}$ He trabajado en la poesía de hijes a partir de Julián Axat, Emiliano Bustos, Francisco Garamona y Ángela Urondo Raboy como así también en poemas inéditos de hijes de detenides desaparecides y sobrevivientes en Chile; dichos textos fueron escritos durante la infancia.
} 


\section{Hasta que mueras de Raquel Robles}

Una joven decide contar ante un escritor la historia de la muerte de hombres y mujeres que tuvieron participación directa con les detenides desaparecides, entre los cuales se cuenta su padre biológico y el compañero de Rita, su madre. La joven Nadia decide narrar desde la cárcel; de modo tal que los lectores asistimos a una literatura por encargo ya que quien escribe es un profesional de las letras que ha regresado del exilio. Aquel es hermano de una víctima de la represión y otrora pareja de una ex presa política que en el relato se identifica con el deíctico personal “ella". Es decir, el relato de Nadia, la historia de su madre (que luego se enamora del escritor), los diferentes relatos de venganza frente a la impunidad, y los avatares de un autor, conjugan un cúmulo de experiencias de familias que fueron atravesadas por el terror de Estado. Como hija, Nadia no cuestiona la militancia de sus padres ni de los compañeres como en Los pequeños combatientes (2013), sino que establece a través de las muertes un hilo de continuidad que gira en torno a una aguda reflexión sobre la derrota. Así, estamos frente a un trabajo de inter memoria, de un diálogo entre madre, compañeres e hija que habilitan problematizar cómo contar desde la literatura, cómo la ficción puede llenar los vacíos de la historia. El texto compagina la historia de treinta y seis asesinatos precedidos por sus respectivos informes jurídico-forenses de los otrora victimarios de detenides políticos. Junto a esto cabe advertir las cintas grabadas desde la cárcel, base de la novelización, y las dudas acerca de las opciones escriturarias del autor a partir de las cuales surgen reflexiones medulares acerca de los límites de la ficción, qué y cómo contar; expresa el personaje autor:

En definitiva la historia de los asesinos siempre venden. Y si el asesino es una chica linda y con un pasado trágico, mucho más. Tendrían que haber elegido a otro. A alguien con un pasado menos complicado, alguien que estuviera más lejos de esos hechos. Pero los muy imbéciles siempre piensan que los que vivimos las mismas desgracias tenemos más 
elementos para escribir sobre ellas. Se dedican a publicar libros y todavía piensan que los escritores escriben sobre sus propias experiencias. Qué ignorantes. (Robles 17)

Sin embargo, lo que resulta de lo enunciado por Nadia, las entrevistas y las muertes filmadas por la joven y entregadas al autor del relato futuro, remiten al lector a hechos del pasado que conocemos, están documentados y a pasajes de la sociobiografía de Robles como indican los agradecimientos de la autora a las personas que pudo acudir para escribir la novela. Si partimos de los oficios de les asesinades por Nadia a los lectores no nos es ajeno que quienes participaron fueron no solo militares sino civiles y religioses; esta dimensión es central y echa luz acerca de la participación civil en la dictadura. Pero Robles se ubica lejos de las dicotomías porque los lectores podemos igualmente recordar, a través del relato de Nadia, a ciudadanes como José, vecino del refugio, que brindaron cobijo o ayuda a las víctimas o los nombres de colaboradores que deja anotado en una extensa lista en el capítulo $\mathrm{V}$.

No menos importante es que el relato proferido por Nadia al escritor es un arduo trabajo de memoria, en el cual explicita que la niña fue partícipe, víctima de la violencia junto con otres niñes a su cuidado; son los "pequeños combatientes" los que remueven el curso de la ficción ya que la casa de campo donde estuvieron escondidos, la protección de José, las visitas de la madre, el dinero conseguido por vía de la abuela, colocan a la niña como centro de la experiencia histórica y que Nadia reconstruye en las entrevistas en el presente del relato. Un ejemplo revelador es cómo aprendió el uso de armas para poder llevar adelante su plan; ante la pregunta del escritor en una entrevista, Nadia responde: "No es que no hubiera tenido un arma en la mano antes, pero aprendí a tirar de verdad con un amigo que tengo en la Fuerza desde largas distancias, a manejar armas cortas. ¿En la policía? Ella se ríe. Sí, en la policía. Me enseñó a matar de un solo tiro" (Robles 187-188). Esto implica que Nadia fue y es una militante, cuyos recuerdos son un acto de reparación de diferentes historias de desaparecides. 
Tanto Elizabeth Jelin, Nora Domínguez como Gabriel Gatti han señalado el trauma de las familias desmembradas por el terror de Estado y el lugar que les cupo a les hijes; la ruptura de la genealogía familiar, las infancias truncadas por la violencia, en el arco que va desde una huida, escondite hasta la desaparición de niñes, son centrales para comprender el relato de la joven quien es hija y madre de les niñes a su cuidado. Gatti alude a "los relatos de la familia rota" en las narrativas del sentido siguiendo las reflexiones de Ludmila Da Silva Catela:

La familia rota es el lugar central de la narrativa del sentido cuando se hace carne entre los afectados. Ludmila da Silva la ha analizado con enorme rigor sabiendo transmitir la extrañeza que para una familia suponía la irrupción de una presencia incómoda, ingestionable ("los hogares eran invadidos, las personas desaparecían, los hermanos eran separados, las abuelas se tornaban madres y los primos hermanos") y las consecuencias que ello implicaba ("las familias se dividían, las personas cambiaban de domicilio, de ciudad, de país. El piso formado por el mundo sentimental de referencias comenzaba a resquebrajarse. La vida cotidiana se partía, marcando un antes y un después, cuya divisoria fuel el secuestro de familiares" (75). Así era, lo normal, ese lugar geométrico hacia el que todo converge, se truncó. (Gatti 171)

Relatos de la destrucción y también del vestigio, de la huella memoriosa. El libro Ni flaco perdón de Dios. Hijos de desaparecidos (edición definitiva, 2017), recopilación de las experiencias de hijes en Argentina realizada por Juan Gelman y Mara La Madrid, es central en este aspecto, ya que recoge escritos en primera persona de un número considerable de hijes, entre los cuales figuran los de ambas autoras. El texto es importante porque los escritos de las otroras jóvenes giran en torno a sus experiencias de infancia; aquellos posibilitan advertir cómo la literatura futura de ambas reacomoda y expone esos fantasmas que están ubicados en un fuera del tiempo sucesivo; en el laboratorio creador también ingresan otros espectros, 
CATEDRAL TomADA: Revista de crítica literaria latinoamericana / Journal of Latin American Literary Criticism Sensible/visible: les hijes de detenides desaparecides en Hasta que mueras, de Raquel Robles (2019) y Yo la quise (2020), de Josefina Giglio

más allá de los pertenecientes a los del mundo familiar; me refiero a la filiación literaria, a los libros que ambas autoras citan en sus respectivas novelas desde Franz Kafka, Humberto Constantini a Ricardo Piglia para dar curso a las memorias. ${ }^{9}$

Robles recurre a la literatura para encarnar a sus fantasmas y configurar su asesina serial, contrafigura de lo que son les hijes y familiares fuera de la ficción que no recurrieron ni a la violencia ni a la venganza; muches de elles esperaron cuarenta años para asistir a un juicio de los victimarios. De modo tal, que desde la literatura y desde la tradición shakespereana, observo la asunción del derecho a narrar cómo deben morir les torturadores, a poner en evidencia que la justicia y sus límites habilita a que la literatura y a través de ella podamos escuchar el "véngame" de Hamlet-padre que acecha y se encarna en la ficción argentina; es decir, la posibilidad de colmar la historia de ficción, otorgarse el permiso de una catarsis histórica y estética a partir del discurso literario. ${ }^{10}$

No menos medular es la reflexión de Elizabeth Jelin (2018) cuando alude al familismo de los 70 y las posibles lecturas que pueden reacomodarlo desde el punto de vista del sentido ante los avances de la agenda de derechos humanos. Fue el terror de Estado que deportó no solo en Argentina, sino en el resto del Cono Sur, a las familias de detenides-desaparecides; despojados de hijes y de otres familiares, al núcleo restante solo le quedó el exilio externo o interno; la lengua del terror operó en el silencio en el período más duro de la dictadura y fue la labor de Abuelas y Familiares la que llevó a cabo una lucha por el sentido, incluso, este acompañó al discurso del silencio en la mayoría de la ciudadanía. Pero fue también el terror de Estado el que impactó en la construcción de un "nosotros", dimensión enunciativa que emerge en las novelas de Robles y de Giglio. Ambas tramas novelescas incorporan a aquelles que no fueron víctimas directas, así, "nosotres los hijes,

\footnotetext{
${ }^{9}$ En ambas autoras la presencia de Ricardo Piglia es central. En el caso de Robles no solo podemos advertir la importancia de los pequeños combatientes de su novela homónima sino también en $L a$ última lectora (2020), se cruza la cita literaria con la presencia central de las infancias.

${ }^{10}$ Félix Bruzzone en Los topos (2008) también recurre al tópico de la venganza. Sin embargo, es posible señalar un tono narrativo diferente al de Robles, que linda la parodia.
} 
nosotres les famililares" implica una ampliación del sentido del colectivo ya que oscila entre la familia nuclear de los herederos legítimos de la agenda, e incorpora a la sociedad civil que no formó parte de ese núcleo originario. ${ }^{11}$

Si partimos de las familias en la novela de Robles advierto que dicho "nosotros" son les familiares de detenides desaparecides y sobrevivientes; estos configuran otra familia hecha de retazos truncados de lo que quedó de la violencia y fueron los que ofrecieron contención durante la dictadura y luego de esta, pero como advertí más arriba, Nadia, a través de José y en la mención de les ciudadanes que brindaron ayuda, configura una comunidad que no formó parte del brazo civil de la dictadura. En tanto que en Giglio la militancia de los 70, les compañeres y la familia sanguínea conviven en el recuerdo de la niña que ha sobrevivido, junto con su hermano Francisco, luego de la detención de Vibel. Las familias constituyen una dimensión central ya que, en primer lugar, permiten advertir otros sentidos y problematizar el lugar que les cupo a las mujeres madres y militantes; estas colisionan con la madre tradicional que los textos matizan en la figura de las abuelas de las niñas. Con respecto a esto señala Nora Domínguez:

La madre guerrillera es una manifestación radicalizada de los modelos femeninos más "progresistas" que traen los años sesenta y setenta. Pero, sin embargo, el encuentro de los dos atributos en una única formación despiertan una disonancia social, un escándalo político, un desarreglo

${ }^{11}$ La rica reflexión de Jelin nos habilita a pensar la ampliación del sentido de colectividad; si bien no se refiere a la literatura de hijes, considero que puede ayudarnos a comprender la familia y el colectivo "nosotros". Expresa la estudiosa: "Por un lado, ¿quiénes constituyen ese "nosotros" con legitimidad para recordar? ¿"un nosotros" que marca la frontera entre quienes pertenecen a la comunidad del hablante y los "otros", que escuchan u observan pero que están claramente excluidos? ¿o un nosotros incluyente, que invita al interlocutor a ser parte de la misma comunidad? Voy a sugerir que hay dos "nosotros" o de comunidad: una inclusiva, la otra excluyente. Las tensiones entre ambas, y los malentendidos y ambigüedades que conllevan, están siempre presentes y pueden tornarse cultural y políticamente significativas en ciertas coyunturas críticas. En consecuencia, la cuestión acerca del clima cultural en la Argentina contemporánea es si el "nosotros" que puede recordar el pasado reciente está reservado a quienes "vivieron" los acontecimientos, o si puede ampliarse para poner en funcionamiento mecanismos de incorporación legítima de otros y otras" (Jelin 215). 
revulsivo e inquietante manifestado especialmente en los sectores dominantes $[\ldots]$.

Que una mujer pudiera estar atravesada por estos dilemas constituía para los sectores más conservadores de la sociedad, aliados del poder militar, una de las mayores "aberraciones". La amenaza que suscita la madre guerrillera para el orden dado se refleja de manera dramática en las acciones que el gobierno militar ejecuta contra las mujeres. La dictadura ataca de forma despiadada sus cuerpos, tortura a las embarazadas arrebatándole sus descendencias. Produce así uno de los delitos más aberrantes que es "la apropiación de niños" y constituye con ello otra de las contracaras asesinas del discurso familiarista y moralizador que difunde y proclama. (289-290)

Otro aspecto de la novelización y de la memoria es que la memoria de Nadia convoca en cada muerto no solo un intento de reparación al margen de la ley, sino los fantasmas en la medida que cada compañere posee una historia familiar, de militancia truncada que la joven les recuerda a los ex victimarios mientras agonizan. Es decir, la recordación es una reparación dolorosa de la creatura de ficción y de la autora; semejante reflexión es válida también para la primera novela de Giglio en la cual recurre a dibujos, fotos y cartas que configuran la trama novelesca.

\section{El diagnóstico médico-jurídico de los 36 cadáveres}

Los 36 cuerpos son presentados ante les lectores, distribuidos en nueve capítulos en los cuales se alterna las historias de los atentados que figuran en las fichas-informes de cada caso, las filmaciones de Nadia, el diario, la historia del escritor, etc. En esta dirección les lectores estamos frente a otras historias que giran alrededor del eje central, como el amor del escritor con una ex presa política, su exilio, el enamoramiento con Rita, madre de Nadia, entre otros. Así, estamos frente 
a un plan de escritura que borra los límites entre una y otra trama; también somos los lectores quienes advertimos los signos de los informes ya que cada uno revela formas de vivir y de morir. Cada cuerpo posee su historia personal y social que la asesina les recuerda; esta confiesa que dio muerte a "funciones", es decir, Nadia hizo blanco en un conjunto de sujetes cuya actividad la regulaba el Estado represor:

Cuenta a quiénes mató -omite a dos- y de qué manera. Pero no dice el nombre de ninguno. Dice que esa información la va a entregar a la fiscalía. Cuando el periodista le pregunta por qué no quiere dar los nombres, ella responde que nuestros muertos tienen nombre propio, los de ellos tienen el nombre de la función. Fueron engranajes de la máquina del mal. (Robles 203-204)

Cada uno posee una identidad civil ya sea policía, colaborador, religiosa, enfermera, etc. a la que se suma las formas en que murieron ya sea por accidente, envenenamiento, estrangulamiento, etc. Considero que cada forma de morir implica una acción y una narración, un recuerdo como magma de la memoria, un fantasma que ronda, una figura de la recordación. Los dos asesinados a los que Nadia se reserva para el final y que integran los treinta y cuatro restantes son los cuerpos de un ex torturador que nunca fue identificado como tal y una partera. Ambos dedicados al tráfico de mujeres y de recién nacidos en la actualidad del relato. Siguiendo la pista de Roberto Bolaño estamos frente a la narrativización de la banalidad del mal ${ }^{12}$ y la consecuente reparación. Los 36 casos son seres deleznables y la pregunta que nos interpela atañe a las limitaciones de la justicia; en este sentido, la ficción desacomoda los lugares asignados por la justicia en casos de lesa humanidad, de allí la larga argumentación que mantiene Nadia con un periodista en la cual este recurre a preguntas acerca de la justicia y los derechos humanos:

\footnotetext{
${ }^{12}$ Me refiero a Estrella distante (1998) de Bolaño. El relato refiere a la historia de una venganza y persecución de la figura literaria del represor Carlos Wieder.
} 
Sólo quiero dejar en claro que en este país se pueden hacer las mayores aberraciones sin que tengan consecuencias. Pero hay juicios contra los represores, le dice el periodista. Sí, dicen ella. Me ocupé de los que zafaron, porque como usted sabrá para poder acusar a alguien se necesita prueba. Alguien los tiene que haber visto, alguien los tiene que poder vincular con los hechos. Y como usted sabrá también se ocuparon muy bien de ocultar todas las pruebas. Bastante han hecho los sobrevivientes reconstruyendo a partir del sonido de las voces, de algo que pudieron ver cuando se caía la venda de los ojos o cuando se levantaba un poco la capucha. (Robles 204)

Así, es preciso señalar la importancia de la nómina de agradecimientos que Robles coloca hacia el final, porque dichos nombres y sus experiencias le brindaron a la autora la materia prima para la novelización.

El texto tensa el juego entre los fantasmas de les compañeres, que están y no están simultáneamente, y los cuerpos-presentes de los victimarios. Nadia está habitada por ese conjunto de espectros que la asedian en su presente, de allí que en el diálogo que mantiene en el límite de la muerte con cada victimario, la joven les recuerde el nombre, su historia, la familia de cada supliciado; Jacques Derrida en Memorias para Paul de Man sostiene que "los fantasmas siempre pasan de prisa, con la voluntad infinita de una aparición furtiva, en un instante sin duración, presencia sin presente de un presente que, al regresar, sólo ronda. En fantasma, le re-venant, el sobreviviente, aparece sólo por medio de la figura o la ficción, pero su parición no es nada, aunque tampoco es mera semblanza." (Derrida 74). Encarnadura de un duelo imposible, el fantasma es una insistencia y magma de las memorias.

Por otra parte, no es su madre la que transgrede en cada acto la impunidad, sino la hija que repara, hace visible la existencia de diversos órdenes familiares, como el de la consanguinidad, de los lazos entre compañeres hasta la forma de crear una familia ficticia a partir del cambio de roles familiares. A partir del relato de la 
familia ampliada las voces tanto de Nadia, _ en Robles_-, como el recuerdo de la "nena", —en Giglio_-, cuestionan los límites de la justicia. Asimismo, Nadia es madre e hija simultáneamente no solo de les niñes a su cuidado, sino de su progenitora. Como ha reflexionado Domínguez las madres guerrilleras conjugan un fuera de lugar a partir del doble estatuto de haber parido hijes y armas, es decir, participar, como Vibel, en secuestros, en la novela de Giglio. Dicha representación materna está lejos del culto mariano, como dispositivo central es la función reproductiva; también las niñas en estas novelas se convierten en pequeñas madres con responsabilidades de adultas militantes. Otro de los aspectos a tener en cuenta en ambos relatos es que comienzan cuando los padres cuando han sido desaparecidos por lo cual el recuerdo se centra en la relación madre-hija. En consecuencia, el género es importante para analizar estas narraciones ya que las hijas de ambas novelas reconstruyen el pasado cuando los padres militantes han muerto. Así, ellas transmiten y retransmiten las memorias.

\section{Yo la quise de Josefina Giglio}

Si la literatura ha hecho suyo el interés por las memorias es el impacto de la pregunta ¿cómo narrar? el que presenta una importante vía de acceso a las mismas. Este problema teórico es también parte de la historia narrada en la novela de Giglio a partir del personaje Ricardo Piglia, en su doble estatuto de docenteinvestigador-escritor y amigo de la madre de la autora. Este no solo emerge en la carta mecanografiada inserta en la cual Piglia alude a la relación con Vibel, sino que aquella extrae de dicha carta el título de su novela. Así, Piglia es el vaso comunicante entre la experiencia de $\operatorname{los} 70$ y la literatura.

La novela está dividida en cuatro capítulos; comienza y culmina con "Yo". La primera persona se refiere a los avatares de un escritor-académico que en el último capítulo advertimos que es Ricardo Piglia. A modo fiel de la balanza entre fragmentos biográficos y la novelización, la presencia del escritor pulsa que el 
relato se incline hacia la segunda. Asimismo, esta dimensión habilita a reflexionar en torno a la capacidad de la literatura para poder escribir desde la ficción el lugar que a esta hija le cupo en la militancia como testiga-protagonista de la recordación.

Yo la quise se asienta en un eje central que es el cambio de la voz narrativa, de allí que la primera persona, dominio de Piglia en el primer y último capítulo, de Vibel en el diario ("Ella") y de la nena que se advierte en la zona difusa de "dice" ("La nena"), implica la doble dirección del texto, es decir, hacer de la experiencia de Piglia una novela, y de la historia novelada de Carlos y Vibel, padres de Giglio, un modo de hacer historia. Esto también se advierte en el último capítulo, "Yo", donde Piglia alude tanto a su posición de escritor como a la experiencia amorosa con Vibel en la juventud que comenzó a desarrollar en el primer capítulo. A partir de dicho discurso es posible advertir el contraste del erotismo con respecto al discurso de Juan Carlos, el militar secuestrado, incluido en el relato de Vibel. En este sentido, es que señalé la importancia de la descripción erótica como dispositivo para visibilizar la(s) política(s) familiar (es); el erotismo del primer capítulo está recreado a partir de un dibujo en el cual quedan expuestas las zonas erógenas de la otrora muchacha militante.

La cultura militante se advierte en el diario de Vibel, que abarca el capítulo "Ella". De esta forma, les lectores nos adentramos a la atmósfera de la época abonadas por las cartas de la joven a la familia entre los años 71 y 74 del siglo pasado. La detención de su pareja, Carlos, la clandestinidad, les compañeres militantes y el cómo narrar tensan la importancia que posee el cambio de la voz narrativa. A modo de zoom la voz itinera entre la primera, a modo de diario, y la tercera persona, que simula una distancia y detalla la escena:

Evito mirar a mi padre a los ojos para que él no me vea llorar todas las noches: mientras me baño, mientras muerdo la almohada para que la nena no se asuste de mi miedo, cuando preparo los fideos con manteca pensando en qué será mañana. Evito mirarlo para que él no se dé cuenta de que estoy llorando ahora mismo mientras hablo con él y repito: 
-Yo no me puedo ir.

—Dejanos los chicos, entonces -insiste mi padre, con una voz ronca que es el remedo de una lejana autoridad.

Lo miro, lo mira, miro a mi hijo dormido a upa de mi madre, mira a la nena que por fin logró hacer un globo grande y rosado que en breve explotará sobre su cara, y digo y dice:

-No.

—Y si a vos te pasa algo, ¿qué va a pasar con los chicos? -nos asalta la voz de mi madre.

-Mamá, si a mí me pasa algo los chicos te los van a dar a vos -respondo con la garganta hueca. Y espanto al cuervo de alas negras para que no nos toque ni siquiera con la punta de sus alas.

La madre no dice nada pero se le nota el desacuerdo en el rictus de la boca, la espalda dura dándose vuelta para hablar con la nena que, convocada al fin a la mesa de los adultos, charlotea sin parar. (78)

La mujer, la maternidad y la militancia en los 70 es una articulación importante ya que permite advertir que Giglio no trabaja con el sentido épico y aurático de la mujer militante; con respecto a esta dimensión Vibel expresa:

No soy la misma madre la que tuvo a la nena que esta madre que ahora suele llorar encima del bebé. Con cada uno soy distinta. No es lo mismo la madre áspera que soy con ella que la dulce madre derramada que puedo ser con él. Con él soy todo sonrisa y ahuecar la mano, con ella el tirón de la ley se siente en mi voz, ella me provoca una ansiedad, un deseo de acabar pronto, de irme del lugar, de quitar su mano del respaldo de mi silla mientras me levanto y me aliso la falda. Sabe mucho de mí, espera mucho de mí. Yo me endurezco. Con él soy remanso y calma, con ella ansiedad y desesperación. Todas esas madres soy. (79) 
De todas esas madres aludidas por Vibel en su relato que aparentemente se asienta en lugares comunes, no lo son si situamos lo enunciado en su contexto, es decir, en los 70 y su posición política en tanto estudiante y militante. En primera persona la mujer hace hincapié en la capacidad de planificar un secuestro de un coronel, junto a sus compañeres, con el fin de negociar la libertad de Carlos, mientras la niña asiste y escucha el plan. Así, cabe conjeturar que la tercera persona que mecha el relato de Vibel es la niña adulta en calidad de escritora. También es preciso señalar que la detención de la joven y el destino de los dos niñes son contados no solo a través del lenguaje verbal sino también a través del dibujo inserto en este apartado; en esta dirección la técnica del distanciamiento, entre el auto que la detiene y el foco que hace centro en partes del cuerpo de les niñes y la madre, narra emocionalmente la detención.

El relato familiar de la mujer militante, con los usos y costumbres de la época, es el reverso de la familia militar; observemos el siguiente ejemplo donde narra la esposa del militar y luego la tercera persona:

Quiero llegar a casa y poner un rato la televisión para pensar en otra cosa. Le dije a Juan Carlos que no trajera la custodia. Es muy cansador estar todo el día con esos tipos de acá para allá. No dicen nada, pero saben todo lo que hago; no puedo ir tranquila ni a lo de Ana María a charlar un rato. Ahora volvemos, la dejamos a mamá en su casa y después, tranquilos a terminar el domingo. Tengo que hacer bañar a los chicos. ¡Qué ganas de ir al cine, a ver una buena película! Hace años que ni pensar en eso.

Necesito una receta de Valium, ya se me terminó la última caja. Pensé en pedirle a Pepe, pero me va a preguntar para qué la quiero y hasta es capaz de negármela. Insiste con el rol de los educadores, pero por suerte Juan Carlos está en Babia, no le presta atención, debe estar pensando en cosas del gobierno. Con lo difícil que está todo.

— ¿Vamos, Juan Carlos? ¿Les digo a los chicos y a mamá? 
—Sí, vamos, vamos. Chau, cuñado -le dice el coronel dándole la mano formalmente al dueño de casa, demasiado formalmente quizá, pero ¿para qué va a disimular confianza y afecto por el bolastraca del hermano de su mujer?

Abraza por la cintura a Susana; la atrae hacia sí con un gesto corto, mandón; la besa en la mejilla, muy cerca de la boca.

Cada día más linda, piensa, con esas tetas increíbles y la muy puta se pone esas camisas que le marcan todo, cómo le metería mano acá mismo, si no fuera por el boludazo impenitente de Pepe, Pepe y todos sus diplomas de médico especialista en enfermedades de viejas y mogólicos, Pepe haciéndose siempre el estudioso, ¿quién se cree que es? ¿Christian Barnard? Si llega a ver un arma se caga en los pantalones. (85-86)

El capítulo "La nena" abarca la historia de la niña de 13 años en Tres Arroyos, provincia de Buenos Aires, quien vive con su hemano Francisco y sus abuelos. En este apartado alude a los usos y costumbres de la familia de clase media; cabe destacar, el despertar de la adolescencia, el intento de envenenamiento fallido y el descubrimiento del cuerpo de la hija. La importancia de esta se advierte a lo largo de novelización ya que es narrada a partir de los puntos de vista de Piglia, de Vibel y del distanciamiento en tercera persona, aludido con antelación, ya que el enunciado "la nena" se reitera en el capítulo homónimo. El "yo" del último capítulo es un retazo de memoria de Piglia, quien como lector refiere a la genealogía de la literatura argentina y la boutade de su pertenencia al campo literario argentino. Me interesa señalar que sus preocupaciones literarias y su trayectoria como profesor y escritor, en los capítulos primero y último, hacen de contrapunto con respecto a la militancia de Vibel. Es decir, como creatura de Giglio y a partir de un documento como es la carta de Ricardo Piglia, la autora puede producir, en el límite entre la literatura y el documento, una vía de acceso a la memoria íntima, emocional. No menos importante, es que la novela se cierra con la foto de Vibel; su rostro completa el dibujo del cuerpo, inserto en el primer capítulo. Así, entre el dibujo y la foto se 
reconstruye su identidad, cuyo cuerpo es trabajado en fragmentos, como las memorias en Yo la quise.

\section{Conclusión}

¿Qué expresa la literatura en torno a las memorias en las novelas seleccionadas? En primer lugar el re ordenamiento, la posibilidad de hacer visible a partir de los fantasmas la experiencia estética del duelo imposible y ubicar el decir, las palabras en otro espacio, diferente al testimonio. Ambas novelas se mueven en el sutil hilo del desacomodamiento que teje la literatura en donde los títulos, la cita, el epígrafe, las lecturas alojan a las memorias de les hijes. Así, aparecen los espectros de aquellos amados que burlan la banalidad del mal, más allá de las imágenes estereotipadas y cristalizadas de les militantes de los 70. La literatura de Robles y Giglio dialoga con les compañeres, padres y madres; el "nosotros" constituye una comunidad que aun en el nuevo milenio necesita ser contada, desde el trastocamiento producido por la violencia. Pero también necesita decirse desde el amor de esa comunidad ampliada. Este decirse desacomoda la permisibilidad, se ubica más allá de las preguntas acerca de la autoridad de quiénes o no pueden narrar e incluso, de las generaciones, de los géneros; este decirse reubica hechos, sujetes (yo-nosotros), recuerdos, legados, filiaciones sanguíneas y literarias y, reitero, el duelo que nunca termina de decirse del todo. 
CATEdRAL Tomada: Revista literaria latinoamericana / Journal of Latin American Literary Criticism Mirian Pino

\section{Bibliografía}

Arenes, Carolina y Pikielny, Astrid. Hijos de los 70. Historias de la generación que heredó la tragedia argentina: Buenos Aires, Sudamericana, 2016.

Basile, Teresa. Infancias. La narrativa argentina de HIJOS. Mar del Plata: Eduvim, 2019.

Colectivo Historias Desobedientes. Escritos desobedientes. Historias de hijos, hijos y familiares de genocidas por la memoria, la verdad y la justicia. Marea editorial: Buenos Aires, 2018.

Derrida, Jacques. Memorias para Paul de Man. Barcelona: Gedisa, 2008. . Los espectros de Marx. El estado de la deuda. El trabajo del duelo y la nueva internacional. Madrid: Trotta, 2012.

Domínguez, Nora. De donde vienen los niños. Maternidad y escritura en la cultura argentina. Buenos Aires: Beatriz Viterbo, 2007.

García Díaz, Teresa. "Ternura y brutalidad: Raquel Robles". Lenguajes de la memoria y los Derechos Humanos III: asedios al archivo, la literatura, los territorios, las pedagogías y la creación. Mirian Pino (ed). Córdoba: Narvaja editor, 2020: 181-192.

Gatti, Gabriel. Identidades desaparecidas. Peleas por el sentido en los mundos de la desaparición forzada. Buenos Aires: Prometeo, 2011.

Gelman, Juan y Lamadrid, Mara. Ni el flaco perdón de Dios. Hijos de desaparecidos. Edición definitiva. Buenos Aires: Planeta, 2017.

Giglio, Josefina. Yo la quise. La Plata: Universidad Nacional de La Plata, 2020. Jelin, Elizabeth. La lucha por el pasado. Buenos Aires: Siglo XXI editores, 2018. Pino, Mirian."Memoria de los padres, memoria de los hijos: Musulmán o biopoética (2013), de Julián Axat. Memoria de la ficción, ficción de la memoria: entre el ritual y la crítica". María Semilla Durán (ed). Alter/nativas, 2018: 431-446

. "Offshore, de Julián Axat: los susurros de la memoria". Tintas. Quaderni di Letterature Iberiche e Iberoamericane, no.7, 2017:161-169. . "La memoria, ese instante en la poesía de Francisco Garamona".

Heterotopías, no 3 (6), 2020: 1-21.

https://revistas.unc.edu.ar/index.php/heterotopias.

. "La dictadura pinochetista y la voz poética de les niñes detenides desaparecides y sobrevivientes" en Teatro, Artes y Prácticas perfomativas del testimonio y la memoria. Nuevos paradigmas, formas, enfoques en las post-dictaduras del Cono Sur. Antonella Cancellier (ed): Universidad de Padova, 2020: 441-455. https://123dok.org/document/1zgwol6y-teatro-practicas-performativastestimonio-memoria-paradigmas-enfoques-dictaduras.html

Rancière, Jacques. Política de la literatura. Buenos Aires: Libros del Zorzal, 2011. . El reparto de lo sensible. Estética y política. Buenos Aires: Prometeo, 2015. 
CATEDRAL TomADA: Revista de crítica literaria latinoamericana / Journal of Latin American Literary Criticism Sensible/visible: les hijes de detenides desaparecides en Hasta que mueras, de Raquel Robles (2019) y Yo la quise (2020), de Josefina Giglio

Reati, Fernando y Cannavaccioulo, Margherita. De la cercanía emocional a la distancia histórica. (Re)presentaciones del terrorismo de Estado, 40 años después. Buenos Aires: Prometeo, 2015.

Robles, Raquel. Hasta que mueras. Buenos Aires: Factotum ediciones, 2019. . La última lectora. Buenos Aires: Fondo de Cultura Económica, 2020. 